\title{
A Preliminary Metabarcoding Study of Prokaryotes in Gökçeada Salt Lake Lagoon, Turkey
}

\author{
Sibel Kucukyildirim Celik ${ }^{1}$ \\ 'Hacettepe University, Faculty of Science, Department of Biology, Ankara, Turkey
}

ORCID IDs of the authors: S.K.C. 0000-0003-2241-3060

Please cite this article as: Kucukyildirim Celik S. A Preliminary Metabarcoding Study of Prokaryotes in Gökçeada Salt Lake Lagoon, Turkey. Eur J Biol 2021; 80(1): 69-74. DOI: 10.26650/EurJBiol.2021.0088

\begin{abstract}
Objective: Microorganisms play an important role in all ecosystem processes and a growing body of molecular and ecological evidence has shown that microbial biodiversity is much more diverse and complex than previously anticipated. This study aimed to determine the prokaryotic microorganisms present in Gökçeada Salt Lake Lagoon.
\end{abstract}

Materials and Methods: A metabarcoding approach was used to determine the microbial diversity in Gökçeada Salt Lake Lagoon.

Results: $16 \mathrm{~S}$ rDNA targeted sequencing revealed 5 Archaea and 31 Bacteria species and Archaea represented 63.2\%. The most frequent Archaea genus was Halorubrum, which belongs to the Euryarchaeota phylum, and the dominant species of Bacteria was Halomonas sulfidaeris (Proteobacteria phylum).

Conclusion: This work will contribute to our understanding of the microbial community structure and composition in coastal lagoons. Hovewer, further surveys will improve our knowledge on microbiota in Gökçeada Salt Lake Lagoon.

Keywords: Biodiversity, halophile, $16 \mathrm{~S}$ rDNA, metabarcoding

\section{INTRODUCTION}

Microorganisms are the most abundant taxonomically and metabolically diverse organisms on Earth. It is well established that microbiota plays an important role in ecosystem stability and sustainability (1). However, biodiversity-based research has mainly focused on plants and animals, giving little attention to microorganisms. In environmental samples, the identification of microorganisms at the species level by conventional techniques is costly, time-consuming, and also continues to be resolved. Recently, many studies have been conducted to provide information about the diversity and distribution patterns of microorganisms, however, it is remarkable that there is still much unknown.

Application of DNA sequence-based methods has led to significant progress in molecular taxonomy and systematics over the last twenty years, revealing re- markably large diversity even in environments that are relatively well studied. For taxonomic purposes, sequencing of the specific regions (i.e. variable regions of $16 \mathrm{~S}, 5 \mathrm{~S}$, or $23 \mathrm{~S}$ rDNA genes) of isolates has resulted in the development of extensive public DNA sequence databases. Moreover, high-throughput sequencing technologies provide an opportunity to generate large amounts of data in a relatively short time. One of the most important advantages of this method is the ability to identify large numbers of species from environmental samples with different characteristics $(2,3)$.

Until recently, microbial biodiversity studies mainly conducted on extreme environments (such as high or low temperature, high or low $\mathrm{pH}$ ) were yet little explored and particularly unique. In this work, the sampling area was a coastal lagoon located in the southeast of Gökçeada Island (Turkey), called Gökçeada Salt Lake Lagoon. The maximum depth of the lagoon is 2 meters, 
and its total area is approximately $2 \mathrm{~km}^{2}$. Coastal lagoons like Gökçeada Salt Lake Lagoon are considered wetlands and have a special hydrological structure formed by a transition zone between fresh and saltwater. Since each wetland ecosystem has its own physicochemical properties, and community structure should be evaluated separately (4).

This study aimed to determine the prokaryotic community structure in Gökçeada Salt Lake Lagoon using a cultureindependent approach that includes metabarcoding based on amplicon sequencing. Metabarcoding is mainly used to characterize species-level diversity in the environmental samples and is considered a method that has the potential to identify rare taxa (5). In addition to the identification of microorganisms at the species-level, information about abundance, distributions, and biological functions of these microorganisms can be obtained by the metabarcoding approach. The high sensitivity and specificity of the method provide an advantage, especially in organisms that cannot be cultured in vitro (6-8). Because previous work is only based on conventional methods $(4,9)$, the prokaryotic diversity in Gökçeada Salt Lake Lagoon is likely limited to only identifiable species. Also, another motivation for this study is that no study focusing on prokaryotic microorganisms in Gökçeada Salt Lake Lagoon has previously been included in the literature. In short, the metabarcoding approach used in this study allows us to determine prokaryotes without prior cultivation and provide a deeper analysis of the prokaryotic diversity in Gökçeada Salt Lake Lagoon.

\section{MATERIALS AND METHODS}

\section{Sampling and Physicochemical Analysis}

To determine the prokaryotic diversity of Gökçeada Salt Lake Lagoon, three water samples (1 Liter of each) were sampled aseptically in September 2019 (407' 47.2" N 25 56' 52.1" E) (Figure 1). All samples were stored at $4^{\circ} \mathrm{C}$ and immediately transported to the laboratory. The analysis of physicochemical parameters (total salinity, major anion and cation concentrations

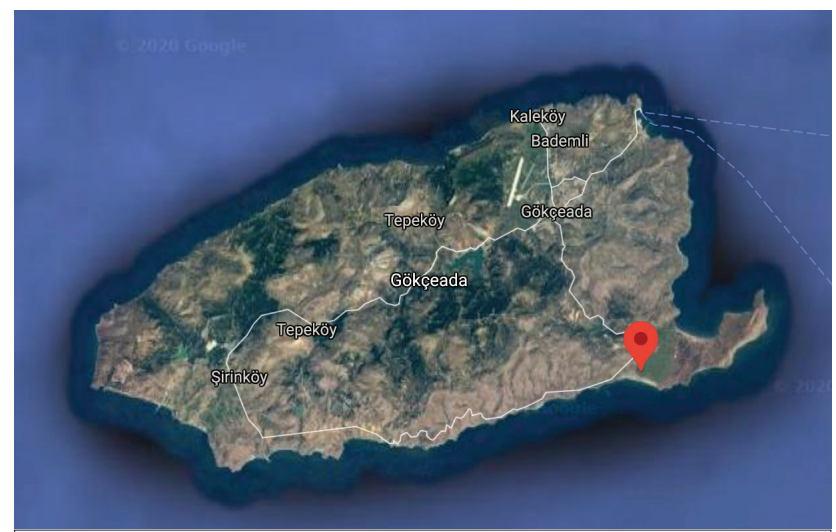

Figure 1. Gökçeada Salt Lake Lagoon in Turkey. The sampling area was shown with a red circle on the map (Satellite imagery: Google/Google Maps (n.d.)).
( $\mathrm{pH}$ and $\mathrm{Na}^{+}, \mathrm{K}^{+}, \mathrm{Ca}^{2+}, \mathrm{Mg}^{2+}, \mathrm{Cl}^{-}, \mathrm{CO}_{3}{ }^{2-}, \mathrm{SO}_{4}{ }^{2-}$ and $\mathrm{NO}_{3}{ }^{-}$) in the samples were performed by Hacettepe University Water Chemistry Laboratory.

\section{DNA Isolation and Sequencing}

For DNA isolation, water samples (500 $\mathrm{ml}$ each) were filtered through a vacuum filter ( $0.22 \mu \mathrm{m}$ filter membrane). Then, filter membranes were cut into small pieces and DNA was isolated using ZymoBIOMICS ${ }^{\circledR}$ DNA Miniprep Kit (Zymo Research, Irvine, CA) according to the manufacturer's instructions. Isolated DNA samples were analyzed on a $1 \%$ agarose gel, and DNA quantity was evaluated using Nanodrop 2000 UV-Vis spectrophotometer (Thermo Fisher, USA). Quantified DNA samples were combined based on equal molarity and were stored at $-20^{\circ} \mathrm{C}$ before analysis.

The sample was processed with the BM Labosis (Turkey) Sequencing Service: Targeted Metabarcoding by using the specific primers that targeting the prokaryotic $16 \mathrm{~S}$ rDNA gene, $(515 \mathrm{~F}$ (5'-GTGYCAGCMGCCGCGGTAA-3') and 806R (5'-GGACTACNVGGGTWTCTAAT-3')) (10-12). The sequencing protocol of the Earth Microbiome Project was used and adapted to the Illumina MiSeq instrument (11). After the amplicon library was prepared, the product was quantified with qPCR fluorescence reading. The library was cleaned using Select-a-Size DNA Clean \& Concentrator $^{\mathrm{TM}}$ (Zymo Research, Irvine, CA). Then, qualitative and quantitative measurement of the library was performed with TapeStation ${ }^{\circledR}$ and Qubit $^{\oplus}$. The sample was sequenced using the Illumina MiSeq instrument following the manufacturer's recommended protocol.

\section{Data Analysis}

Raw data were processed and read quality was controlled by FastQC and QIIME2. DADA2 was used to obtain specific amplicon sequences and chimeric sequences were excluded from the analysis using the same program (13). QIIME2 was used to cluster DNA sequence data with more than $97 \%$ similarity as operational taxonomic units (OTUs) $(14,15)$ and chimeric OTUs were extracted from the dataset using USEARCH algorithm (16). Taxonomic assignments of OTUs were performed using the QIIME2 pipeline (15) and SILVA database using a 70\% confidence level cutoff for assignment (17). Raw sequencing data were recorded in the NCBI database (PRJNA517326). Figure 2 was prepared using Krona (18).

\section{RESULTS AND DISCUSSION}

\section{Physicochemical analyses}

During sampling, temperature and $\mathrm{pH}$ were measured as $20.9^{\circ} \mathrm{C}$ and 6.98, respectively. The physicochemical properties of the samples are shown in Table 1. Sodium $\left(\mathrm{Na}^{+}\right)$and Chloride $\left(\mathrm{Cl}^{-}\right)$ ions were found to have the highest concentration in the samples. According to the chemical composition of the Lagoon, it can be expected that halophilic organisms dominate in this environment.

After 16S rDNA sequencing, 57,847 high-quality paired-end reads were obtained. The number of identified prokaryotic 
A
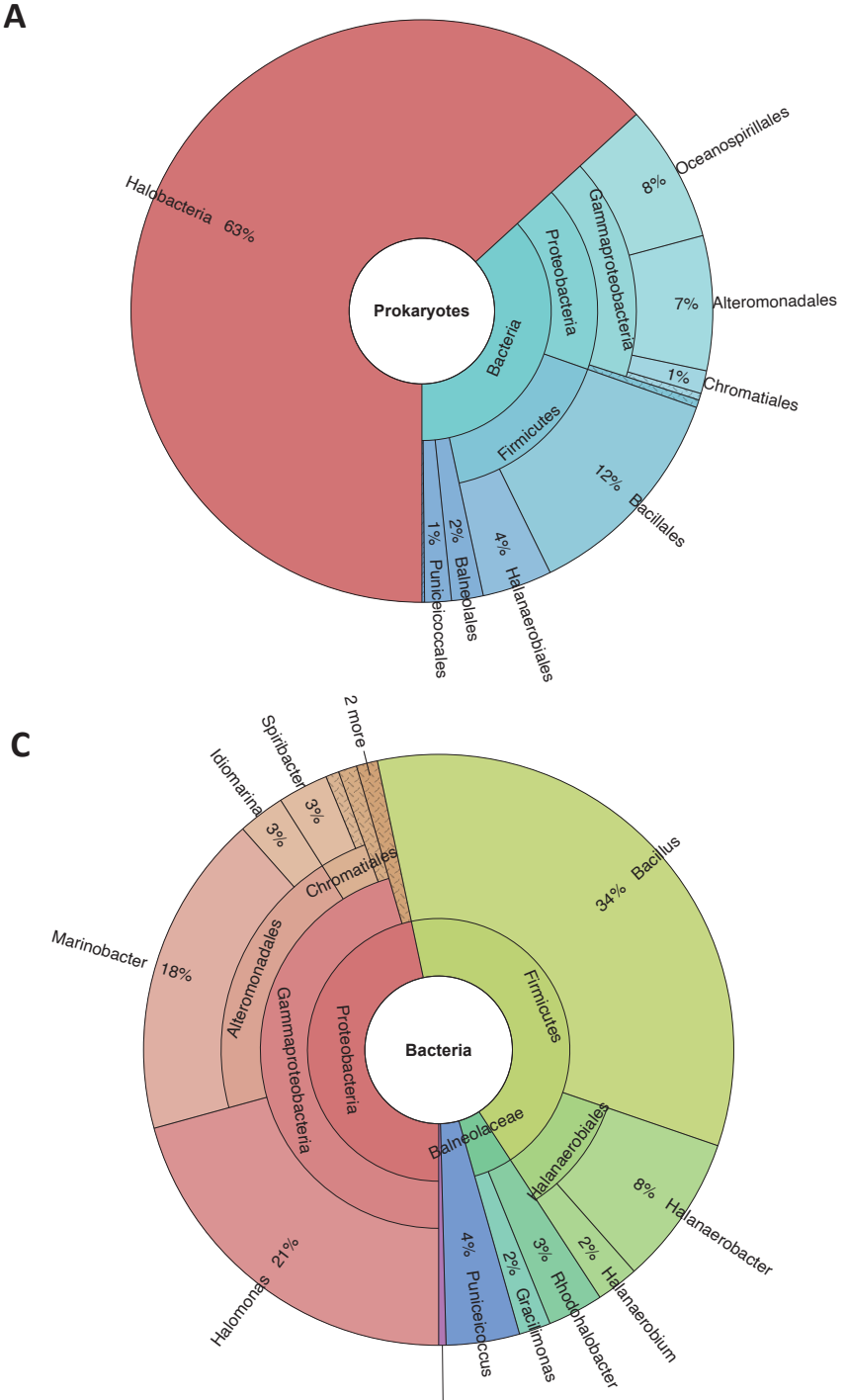

B

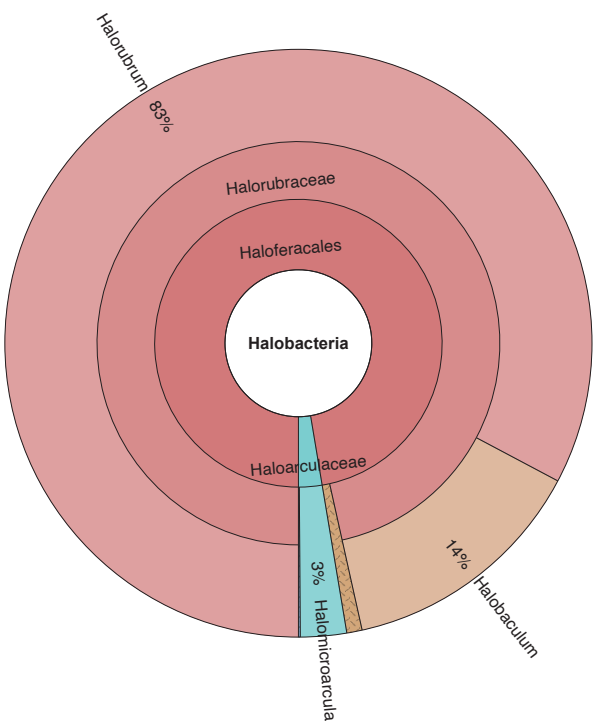

Longimonas halophila $\quad 0.4 \%$

Figure 2. Relative distributions of prokaryotes (A), Archaea (B) and Bacteria (C) as obtained from 16S rDNA metabarcoding data.

Table 1. Physicochemical properties of the samples collected from Gökçeada Salt Lake Lagoon (ion concentrations in $\mathrm{g} / \mathrm{L}$ ).

\begin{tabular}{llllllllll}
\hline & Temperature $\left({ }^{\circ} \mathbf{C}\right)$ & $\mathbf{p H}$ & $\mathbf{N a}^{+}$ & $\mathbf{K}^{+}$ & $\mathbf{C a}^{2+}$ & $\mathbf{M g}^{2+}$ & $\mathbf{H C O}_{\mathbf{3}}{ }^{-}$ & $\mathbf{C l}^{-}$ \\
\hline Average & 20.9 & 6.98 & 111.63 & 3.47 & 2.27 & 16.07 & 0.24 & 225.12 \\
\hline
\end{tabular}

species in the sample was found to be 36 by comparison of OTUs with the SILVA database (Table 2). Despite $63.2 \%$ of the sample consisting of Archaea members, only 5 archaeal species were determined (Figure 2A). The most abundant genus of Archaea was Halorubrum (82.7\%), and the others were Halobaculum (13.7\%), Halomicroarcula (2.5\%), Halobellum $(0.8 \%)$, and Halosimplex $(0.1 \%)$ (Figure $2 \mathrm{~B})$. Metagenomic and metabarcoding approaches were previously used to investigate microbial compositions of different hypersaline environments $(6,19,20)$, and the Archaea was previously described as the dominant group in these environments $(21,22)$. As observed in this study, Halorubrum was previously reported among dominant archaeal genera in salt lakes and salterns $(23,24)$. 
Eur J Biol 2021; 80(1): 69-74

Kucukyildirim Celik. Prokaryotes in Gökçeada Salt Lake Lagoon

Table 2. Species detected in this study via metabarcoding approach

\begin{tabular}{|c|c|c|c|c|}
\hline Organism & & & No. of reads & $\%$ \\
\hline Prokaryotes & Archaea & Halorubrum sp. & 3922 & 52.30 \\
\hline Prokaryotes & Archaea & Halobaculum sp. & 652 & 8.69 \\
\hline Prokaryotes & Bacteria & Halomonas sulfidaeris & 462 & 6.16 \\
\hline Prokaryotes & Bacteria & Bacillus persicus & 420 & 5.60 \\
\hline Prokaryotes & Bacteria & Bacillus litoralis & 350 & 4.67 \\
\hline Prokaryotes & Bacteria & Marinobacter aquaticus & 261 & 3.48 \\
\hline Prokaryotes & Bacteria & Marinobacter flavimaris & 168 & 2.24 \\
\hline Prokaryotes & Archaea & Halomicroarcula sp. & 120 & 1.60 \\
\hline Prokaryotes & Bacteria & Puniceicoccus vermicola & 111 & 1.48 \\
\hline Prokaryotes & Bacteria & Halanaerobacter lacunarum & 100 & 1.33 \\
\hline Prokaryotes & Bacteria & Halomonas fontilapidosi & 91 & 1.21 \\
\hline Prokaryotes & Bacteria & Rhodohalobacter halophilus & 84 & 1.12 \\
\hline Prokaryotes & Bacteria & Halanaerobacter salinarius & 78 & 1.04 \\
\hline Prokaryotes & Bacteria & Spiribacter aquaticus & 76 & 1.01 \\
\hline Prokaryotes & Bacteria & Idiomarina atlantica & 71 & 0.95 \\
\hline Prokaryotes & Bacteria & Bacillus pseudofirmus & 49 & 0.65 \\
\hline Prokaryotes & Bacteria & Halanaerobacter jeridensis & 49 & 0.65 \\
\hline Prokaryotes & Bacteria & Halanaerobium praevalens & 47 & 0.63 \\
\hline Prokaryotes & Bacteria & Marinobacter persicus & 47 & 0.63 \\
\hline Prokaryotes & Bacteria & Bacillus mesophilus & 41 & 0.55 \\
\hline Prokaryotes & Archaea & Halobellus sp. & 40 & 0.53 \\
\hline Prokaryotes & Bacteria & Bacillus thioparans & 37 & 0.49 \\
\hline Prokaryotes & Bacteria & Gracilimonas halophila & 34 & 0.45 \\
\hline Prokaryotes & Bacteria & Bacillus hemicellulosilyticus & 30 & 0.40 \\
\hline Prokaryotes & Bacteria & Hydrogenovibrio halophilus & 28 & 0.37 \\
\hline Prokaryotes & Bacteria & Guyparkeria hydrothermalis & 20 & 0.27 \\
\hline Prokaryotes & Bacteria & Arcobacter group & 18 & 0.24 \\
\hline Prokaryotes & Bacteria & Halanaerobium saccharolyticum & 17 & 0.23 \\
\hline Prokaryotes & Bacteria & Gracilimonas tropica & 14 & 0.19 \\
\hline Prokaryotes & Bacteria & Marinobacter salinus & 13 & 0.17 \\
\hline Prokaryotes & Bacteria & unknown & 11 & 0.15 \\
\hline Prokaryotes & Bacteria & Halomonas glaciei & 11 & 0.15 \\
\hline Prokaryotes & Bacteria & Ruegeria intermedia & 8 & 0.11 \\
\hline Prokaryotes & Bacteria & Halomonas zhaodongensis & 8 & 0.11 \\
\hline Prokaryotes & Bacteria & Desulfohalobium sp. & 6 & 0.08 \\
\hline Prokaryotes & Archaea & Halosimplex sp. & 5 & 0.07 \\
\hline Total & & & 7499 & \\
\hline
\end{tabular}


A total of 31 bacterial species were identified (Table 2). Proteobacteria were the dominant bacterial phylum $(47 \%$ of bacteria) and followed by Firmicutes (44\% of bacteria). Bacillus (33.6\%), Halomonas (20.7\%), Marinobacter (17.7\%), Halanaerobacter $(8.2 \%)$ were the most common and most abundant bacterial genera in the sample analyzed (Figure $2 \mathrm{C})$. Considering the chemical composition of the Lagoon, the presence of halophilic bacterial genera such as Salinibacter could be expected (25). However, our analysis did not find any OTU related to Salinibacter, which may be a result of the abundance of some haloarchaeal species (e.g. Halorubrum), which can inhibit Salinibacter growth as previously suggested by Anton et al. (26).

In conclusion, in this study, the prokaryotic diversity of Gökçeada Salt Lake Lagoon was evaluated, and Euryarchaeota, Proteobacteria, and Firmicutes members were found to be essential components of its prokaryotic community. This study allows us to improve our knowledge of the prokaryotic community structure in the sampling area. But a more comprehensive microbiome analysis can be obtained with future metabarcoding/metagenomic analyses by focusing on both prokaryotic and eukaryotic microbes. In addition, although OTUs that cannot be associated with any taxa are relatively few in this study, OTUs still have the potential to contribute to the identification of new organisms. In future studies, it is planned to collect samples from different depths and locations of the lake and elaborate the analyses to enlighten complete microbial diversity and microbial community structure.

Peer-review: Externally peer-reviewed.

Conflict of Interest: The author declare that she has no conflicts of interest to disclose.

Financial Disclosure: There are no funders to report for this submission.

\section{REFERENCES}

1. Wardle DA. Communities and ecosystems: Linking the aboveground and below-ground components. Princeton, NJ: Princeton University Press; 2002.

2. Leininger S, Urich T, Schloter M, Schwark L, Qi JW, Nicol G, et al. Archaea predominate among ammonia-oxidizing prokaryotes in soils. Nature 2006; 442: 806-9.

3. Sogin ML, Morrison HG, Huber JA, Welch DM, Huse SM, Neal PR, et al. Microbial diversity in the deep sea and the underexplored "rare biosphere". PNAS 2006; 103: 12115-20.

4. Aslan H, Gonulal O, Can-Yilmaz E, Elipek B, Baytut O, Tosunoglu M, et al. Species diversity in lentic, lotic, marine and terrestrial biotopes of Gokceada Salt Lake Wetland (Canakkale, Turkey). Fresenius Environ Bull 2018; 5: 2853-66.

5. Taberlet P, Coissac E, Pompanon F, Brochmann C, Willerslev E. Towards next-generation biodiversity assessment using DNA metabarcoding. Mol Ecol 2012; 21: 2045-50.
6. Fouts DE, Szpakowski S, Purushe J, Torralba M, Waterman RC, et al. Next generation sequencing to define prokaryotic and fungal diversity in the bovine rumen. PLoS One 2012; 7: e48289.

7. Pavan-Kumar A, Gireesh-Babu P and Lakra WS. DNA Metabarcoding: A new approach for rapid biodiversity assessment. J Cell Sci Mol Biol 2015; 2: 111.

8. Abdelfattah A, Malacrinò A, Wisniewski M, Cacciola SO, Schena L. Metabarcoding: a powerful tool to investigate microbial communities and shape future plant protection strategies. Biol Control 2017; 120: 1-10.

9. Bassler-Veit B, Barut IF, Merc E, Avsar N, Nazik A, Kapan-Yesilyurt $S$, et al. Distribution of microflora, meiofauna, and macrofauna assemblages in the hypersaline environment of northeastern Aegean Sea coasts. J Coast Res 2013; 29: 883-98.

10. Amaral-Zettler LA, McCliment EA, Ducklow HW, and Huse SM. A method for studying protistan diversity using massively parallel sequencing of $\mathrm{V} 9$ hypervariable regions of small-subunit ribosomal RNA Genes. PLoS One 2009; 4: e6372.

11. Caporaso JG, Lauber CL, Walters WA, Berg-Lyons D, Huntley J, Fierer N, et al. Ultra-high-throughput microbial community analysis on the Illumina HiSeq and MiSeq platforms. ISME J 2012; 6: 1621-4.

12. Walters W, Hyde ER, Berg-Lyons D, Ackermann G, Humphrey G, Parada A, et al. Improved bacterial 16S rRNA gene (V4 and V4-5) and fungal internal transcribed spacer marker gene primers for microbial community surveys. mSystems 2016; 1: e00009-15.

13. Callahan BJ, McMurdie PJ, Rosen MJ, Han AW, Johnson AJA, Holmes S. DADA2: High resolution sample inference from Illumina amplicon data. Nat Methods 2016; 13: 581-3.

14. Caporaso JG, Kuczynski J, Stombaugh J, Bittinger K, Bushman FD, et al. QIIME allows analysis of high throughput community sequencing data. Nat Methods 2010; 7: 335-6.

15. Bolyen E, Rideout JR, Dillon MR, et al. Reproducible, interactive, scalable and extensible microbiome data science using QIIME 2. Nat Biotechnol 2019; 37: 852-7.

16. Edgar RC. UPARSE: Highly accurate OTU sequences from microbial amplicon reads. Nature Methods 2013; 10: 996-8.

17. Yilmaz P, Parfrey LW, Yarza P, Gerken J, Pruesse E, Quast C, et al. The SILVA and "All-species Living Tree Project (LTP)" taxonomic frameworks. Nucleic Acids Res 2014; 42: 643-8.

18. Ondov BD, Bergman NH, Phillippy AM. Interactive metagenomic visualization in a Web browser. BMC Bioinform 2011; 12: 385.

19. Ghai $R$, Pašić $L$, Fernández $A B$, Martin-Cuadrado $A B$, Mizuno $C M$, McMahon KD, et al. New abundant microbial groups in aquatic hypersaline environments. Sci Rep 2011; 1: 135.

20. Fernandez AB, Ghai R, Martin-Cuadrado AB, Sanchez-Porro C, Rodriguez-Valera $F$, Ventosa A. Prokaryotic taxonomic and metabolic diversity of an intermediate salinity hypersaline habitat assessed by metagenomics. FEMS Microbiol Ecol 2014; 88: 623-35.

21. Oren A. Life at high salt concentrations. In: Dworkin M, Falkow $S$, Rosenberg $\mathrm{E}$, Schleifer K-H, Stackebrandt E, editors. The prokaryotes. A handbook on the biology of bacteria: ecophysiology and biochemistry, vol 2. New York: Springer; 2011. p. 263-82.

22. Simachew A, Lanzén A, Gessesse A, Øvreås L. Prokaryotic community diversity along an increasing salt gradient in a soda ash concentration pond. Microb Ecol 2016; 71: 326-38.

23. Mutlu MB, Martinez-Garcia M, Santos F, Pena A, Guven K, Anton J. Prokaryotic diversity in Tuz Lake, a hypersaline environment in inland Turkey. FEMS Microbiol Ecol 2008; 65: 474-83.

24. Mutlu MB, Guven K. Bacterial diversity in Çamaltı Saltern, Turkey. Pol J Microbiol 2015; 64: 37-45. 
Eur J Biol 2021; 80(1): 69-74

Kucukyildirim Celik. Prokaryotes in Gökçeada Salt Lake Lagoon

25. Elevi Bardavid R, lonescu D, Oren A, Rainey FA, Hollen BJ, Bagaley $\mathrm{DR}$, et al. Selective enrichment, isolation and molecular detection of Salinibacter and related extremely halophilic Bacteria from hypersaline environments. Hydrobiologica 2007; 576: 3-13.
26. Anton J, Pena A, Santos F, Martinez-Garcia M, Schmitt-Kopplin P, Rossello-Mora R. Distribution, abundance and diversity of the extremely halophilic bacterium Salinibacter ruber. Saline Syst. 2008; 4: 15 . 